\title{
Antenna array design on flexible substrate for wireless power transfer
}

\author{
Habeeba Khan, Sayyed Arif Ali and Mohd Wajid \\ Department of Electronics Engineering, Z.H.C.E.T., Aligarh Muslim University, \\ Aligarh, India, and \\ Muhammad Shah Alam \\ Electrical Engineering Department, College of Engineering, \\ Imam Mohammad Ibn Saud Islamic University, Riyadh, Saudi Arabia
}

\begin{abstract}
Purpose - In this work, a microstrip antenna array for wireless power transfer (WPT) application is reported. The proposed $4 \times 4$ antenna array operating at $16 \mathrm{GHz}$ is designed using a flexible Kapton polyimide substrate for a far-field charging unit (FFCU).

Design/methodology/approach - The proposed antenna is designed using the transmission line model on a flexible Kapton polyimide substrate. The finite element method (FEM) is used to perform the full-wave electromagnetic analysis of the proposed design.

Findings - The antenna offers $-10 \mathrm{~dB}$ bandwidth of $240 \mathrm{MHz}$ with beam width and broadside gain found to be $29.4^{\circ}$ and $16.38 \mathrm{~dB}$, respectively. Also, a very low cross-polarization level of $-34.23 \mathrm{~dB}$ is achieved with a radiation efficiency of $36.67 \%$. The array is capable of scanning $-15^{\circ}$ to $+15^{\circ}$ in both the elevation and azimuth planes.

Originality/value - The radiation characteristics achieved suggest that the flexible substrate antenna is suitable for wireless charging purposes.

Keywords Far-field charging unit (FFCU), Flexible substrate, Kapton polyimide, Microstrip array antenna, Phased-array, Wireless charging, Wireless power transfer (WPT)

Paper type Research paper
\end{abstract}

\section{Introduction}

With the advancement of mobile technology, devices such as wearables, tablets and smartphones get used for longer duration. With this development, it is necessary to keep the devices adequately charged all the times. Most of these devices do not require cords for data connectivity, however, charging still demands tying up these devices with a wire (Patil and Padaganur, 2018). The goal of wireless power is to remove these cables and wirelessly transmit power to charge these devices (Sharma, 2016; Heo et al., 2017). Wireless power transfer (WPT) is a generic term for transmitting energy through electromagnetic fields (Lu et al., 2016). In general, WPT consists of a transmitter device connected to a source of power, which converts the power to a time-varying electromagnetic field and a receiver that receive the power and converts it back to dc

(C) Habeeba Khan, Sayyed Arif Ali, Mohd Wajid and Muhammad Shah Alam. Published in Frontiers in Engineering and Built Environment. Published by Emerald Publishing Limited. This article is published under the Creative Commons Attribution (CC BY 4.0) licence. Anyone may reproduce, distribute, translate and create derivative works of this article (for both commercial and non-commercial purposes), subject to full attribution to the original publication and authors. The full terms of this licence may be seen at http://creativecommons.org/licences/by/4.0/legalcode

Authors acknowledge Prof. Syed Azeemuddin, Centre of VLSI and EMBEDDED SYSTEM, IIIT, Hyderabad for his motivation and guidance.

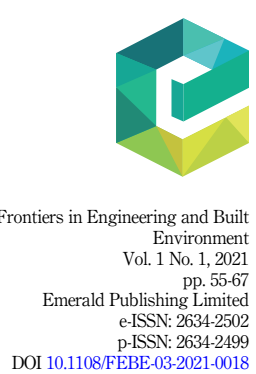


FEBE 1,1

\section{6}

Figure 1.

Antenna array for FFCU to wirelessly transfer power in indoor scenario or ac electric current and used for charging the mobile device (Lu et al., 2016). The WPT promises to eliminate the use of wires and batteries, thus increasing the mobility, convenience and safety of mobile devices (Ibrahim et al., 2016). Moreover, using this technique, power is wirelessly transferred even where interconnecting wires are inconvenient, hazardous, or not possible.

There are mainly two techniques of power transfer, namely near field and far-field. In the first category, power is transferred over short distances by magnetic fields using inductive and capacitive coupling (Erfani et al., 2017, 2018a, b). Inductive coupling is the most widely used for applications like charging of mobile phones, induction cooking and wirelessly charging of implantable medical devices like artificial cardiac pacemaker (Basnayaka et al., 2020). However, in far-field technique, also called power beaming, power is transferred by electromagnetic radiation beams, like microwaves (García et al., 2019), which could transport power over long distance and delivered to the receiver. Their applications include solar power satellites and wireless powered drone aircrafts (Bush, 2014).

As shown in Figure 1, power is wirelessly transferred to a user terminal in indoor scenario from a distantly placed far-field charging unit (FFCU) consisting of an array antenna to focus the electromagnetic radiation toward the terminal. rectennas within the terminal rectify the received signal. WPT enables the charging of devices more conveniently as well as easy to use. Of course, there is no hassle involved in cabling and plugging. Although WPT is not a new concept (Sheik Mohammed et al., 2014), its history goes back to 1830, when the concept introduced by Faraday's was first used inductive coupling to transfer power wirelessly. The various technologies developed thereafter for wireless transfer of power are summarized in Table 1.

Most of the papers are based on inductive coupling that allows power transfer through near field radiations, only few papers claim for far-field WPT (Dunbar et al., 2015; Jadidian and Katabi, 2014). Generally, antennas designed for WPT are based on fixed substrate (Heo et al., 2017).

Recently few papers claimed to design conformal antenna (Hashemi et al., 2019; Peng et al., 2020; Pham et al., 2011; Subbaraman et al., 2013) but they are not used for power transfer. Very few efforts are found in literature where flexible substrates were used for power transfer (Bakytbekov et al., 2018; Bao et al., 2019; Haerinia and Noghanian 2019;

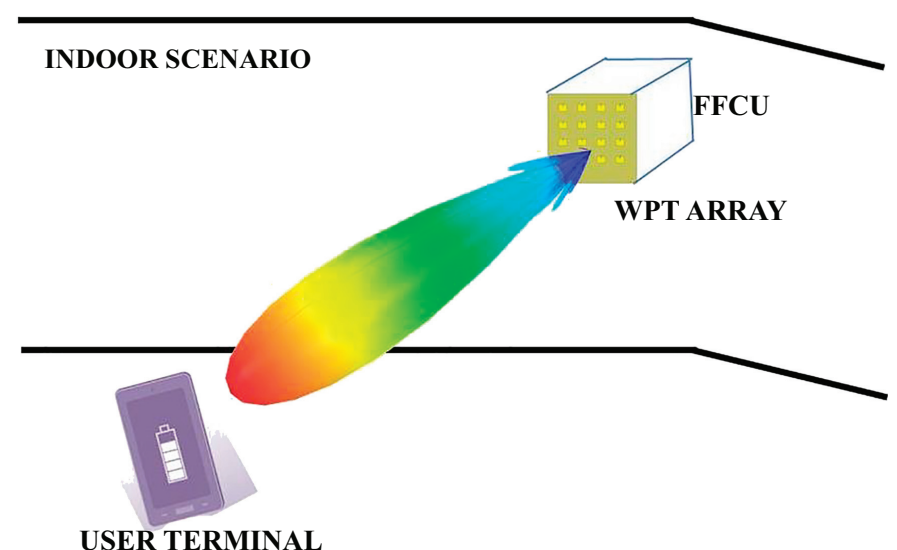




\begin{tabular}{|c|c|c|c|c|}
\hline Technology & Devices & Range & Frequency & I array \\
\hline $\begin{array}{l}\text { Inductive } \\
\text { coupling }\end{array}$ & Wire coils & $\begin{array}{l}\text { Millimeters to centimeters } \\
\text { (Choudhary et al., 2011) }\end{array}$ & Below $100 \mathrm{kHz}$ & flexibl \\
\hline $\begin{array}{l}\text { Magnetic } \\
\text { resonant } \\
\text { coupling }\end{array}$ & $\begin{array}{l}\text { Tuned wire coils, } \\
\text { lumped element } \\
\text { resonators }\end{array}$ & $\begin{array}{l}\text { A few meters, typically } 4 \text { to } 10 \\
\text { times the coil diameter (Rayes } \\
\text { et al. 2016) }\end{array}$ & $\begin{array}{l}\text { Hundreds of } \mathrm{MHz}-\mathrm{GHz} \\
\text { (Jadidian and Katabi, } \\
\text { 2014) }\end{array}$ & \\
\hline EM radiation & $\begin{array}{l}\text { Dish antenna, antenna } \\
\text { array, rectenna }\end{array}$ & $\begin{array}{l}\text { Several meters to hundreds of } \\
\text { kilometers }\end{array}$ & $\begin{array}{l}800 \mathrm{MHz} \text { to } 94 \mathrm{GHz} \\
\text { (Valenta and Durgin, }\end{array}$ & 5 \\
\hline $\begin{array}{l}\text { Laser power } \\
\text { beaming }\end{array}$ & $\begin{array}{l}\text { Laser emitter, } \\
\text { photovoltaic receiver }\end{array}$ & Up to kilometers & $\begin{array}{l}\text { 2014) } \\
\text { THz }\end{array}$ & $\begin{array}{r}\text { Table 1. } \\
\text { Technologies for } \\
\text { wireless power transfer }\end{array}$ \\
\hline
\end{tabular}

Heo et al., 2017; Palazzi et al., 2018). To the author's best knowledge this is first time an array antenna is investigated on flexible Kapton polyimide substrate as a transmitting antenna as oppose to receiving rectennas used in RF harvesting systems. Kapton polyimide is both conformable and light weight. Proposed array antenna has broadside gain and beam width value of $16.38 \mathrm{~dB}$ and $29.4^{\circ}$, respectively. The measured results for the proposed antenna are not included due to the restriction imposed by the COVID-19 pandemic. This paper is organized as follows: Section 2 provides details about substrate selection and the antenna design. The results are discussed in section 3 , and finally, conclusions are drawn in section 4.

\section{Antenna design}

\subsection{Choice of substrate}

The antenna substrate choice depends on dielectric properties, susceptibility to miniaturization, resistance to mechanical deformations, i.e. bending, wrapping and twisting and endurance in the external environment (Kirtania et al., 2020). In general, 3 types of substrate are used for flexible antenna design.

\section{(1) Thin glass \\ (2) Metal foils \\ (3) Plastic/polymer}

Later one is generally used because glass is brittle, and metallic foils are costly, and surface roughness is more environmental (Kirtania et al., 2020). Flexible substrates nowadays are preferred over fixed substrates because they are cheap, light weight and durable (Wong and Salleo, 2009).

As observed from Table 2, it can be seen that Kapton has very good chemical and mechanical properties among other commonly used flexible substrate like PET (polyethylene terephthalate), PEN (polyethylene naphthalene) and LCP (liquid crystalline polymers).

\begin{tabular}{|c|c|c|c|c|c|c|}
\hline Material & PET & PEN & Kapton & LCP & Paper & \\
\hline Mechanical properties & Good & Good & Excellent & Good & - & $\begin{array}{r}\text { Table } 2 . \\
\text { Properties of different }\end{array}$ \\
\hline Heat resistance & Low & Very good & Excellent & Good & - & flexible substrates \\
\hline Chemical resistance & Good & Good & Good & Excellent & - & (Wong and \\
\hline Electrical properties & Good & Good & Good & Good & Good & Salleo, 2009) \\
\hline
\end{tabular}


FEBE 1,1

\section{8}

Figure 2.

Proposed unit microstrip patch antenna on Kapton substrate
Moreover, Kapton has minimum tangent loss value among PET and PEN (Kirtania et al., 2020). Both PET and PEN provide excellent conformability but these substrates cannot resist high temperature (Kirtania et al., 2020). Therefore, Kapton is chosen as substrate for antenna design having substrate thickness $(h)=0.127 \mathrm{~mm}$ and dielectric constant $\left(\varepsilon_{\text {sub }}\right)=3.2$ and $\tan \delta=0.012$ (Yang et al., 2016).

\subsection{Microstrip patch antenna}

Microstrip antenna, in its most basic form, comprises of two thin metallic layers separated by a dielectric. Top metallic layer having specific shape behaves as radiating patch and the bottom metallic layer act as a ground plane and a dielectric substrate sandwiched between the two plates. Generally, copper and gold are used as metallic radiating layer due to their high conductivity. The patch can be of any shape but simple shapes are preferred because basic shapes are easy to analyze by the available theoretical models. Square, rectangular, dipole, triangular, elliptical and circular are some basic shapes that are used for patch antenna. However, in this paper a rectangular patch is used instead of circular patch because it has demonstrated higher gain (Balanis, 2005). Different types of feeding techniques are available for patch antennas. In general, a patch antenna, which is fed either by coaxial line or strip line. The current and voltage in the patch is $90^{\circ}$ out of phase.

Using the transmission line model, and operating frequency $\left(f_{0}\right)$, height $(h)$ and dielectric constant of the substrate $\varepsilon_{\text {sub }}$, the size of the patch and ground planes are determined (Balanis, 2005). The microstrip patch antenna is used as it is one that offers light weight and is low profile (Gangwar and Alam, 2016). It is a wide beam narrowband antenna which can be manufactured easily by the printed circuit technology. The size of microstrip antenna is usually related to its operating wavelength that is $\frac{\lambda}{2}$ (Balanis, 2005). The design of proposed microstrip antenna with all its parameters is shown in Figure 2.

Although, the ground plane is assumed to be infinite in transmission line model, in all practical scenario, finite size plane is used. By substituting $f_{o}, h, \varepsilon_{\text {sub }}$ and $c$, the dimensions of

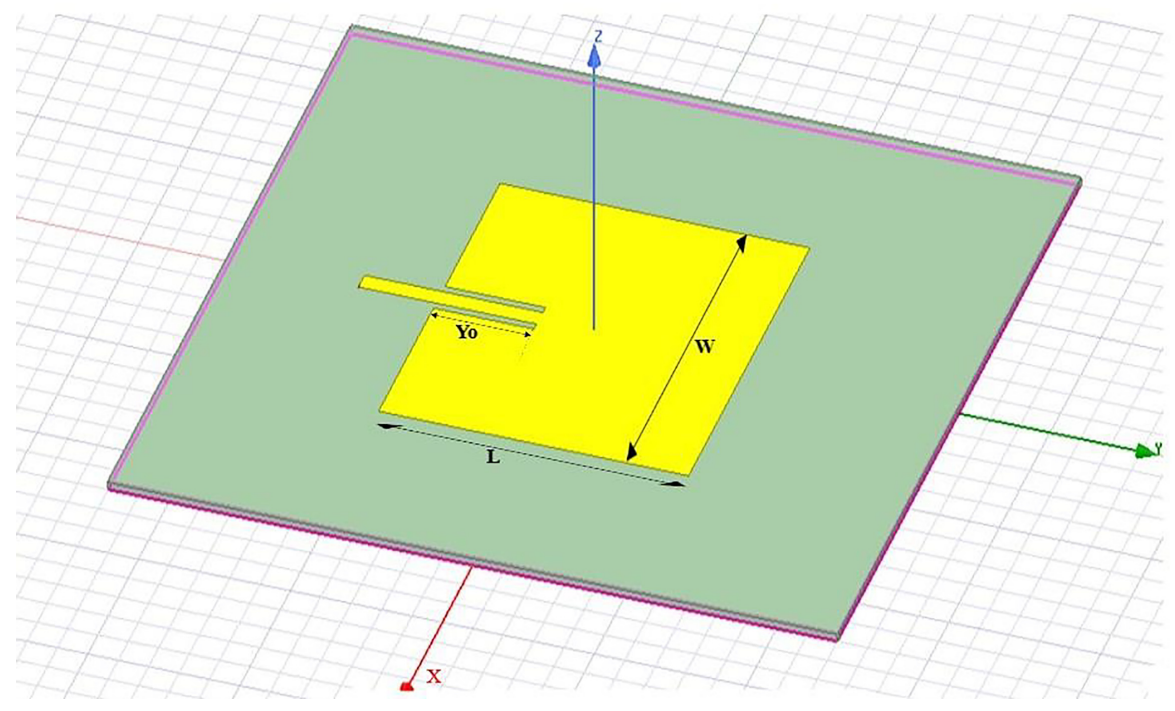


patch are calculated. Length and width of the patch antenna calculated to be 5.1 and $6.47 \mathrm{~mm}$ respectively.

The inset length of the patch $\left(y_{0}\right)$ as shown in Figure 2 is calculated such that the input impedance of the patch is equal to the characteristic impedance of the feed line which is $50 \Omega$.

$$
R_{\text {Input }}\left(y=y_{0}\right)=R_{\text {Input }}(y=0)\left(\frac{\pi}{L} y_{0}\right)
$$

Where, $R_{\text {Input }}(y=0)$ is the input impedance at the leading radiating edge of the patch and $R_{\text {Input }}\left(y=y_{0}\right)$ is the characteristic input impedance $(50 \Omega)$. The antenna is fed using an inset microstrip feed having dimensions $2.9 \times 0.305 \mathrm{~mm}$. The ground plane is defined by perfect electric conductor boundaries. An air box must be specified as open space in the model, so that radiation from the design is absorbed and not re-reflected. The air box needs to be quarter- wavelength long (Balanis, 2005). The length, width and height of air box in the design is $42.75 \mathrm{~mm} \times 42.75 \mathrm{~mm} \times 18.87 \mathrm{~mm}$ respectively.

\subsection{Antenna array}

An antenna array consists of $N$ spatially separated radiating elements. Each element has its own induction field. The elements are placed such that each one lies in the neighboring one's induction field. Therefore, the overall radiation pattern produced by them would be the vector sum of the individual elements (Balanis, 2005). Array antenna is used to enhance performance like increasing directivity and gain.

Single elements are used to design antenna array with proper inter-element spacing, generally $\frac{\lambda}{2}$ along both $x$ and $y$ axis. Array antennas can transfer power at much larger distance compared to single element. Figure 3 shows $4 \times 4$ proposed square array with inter-element spacing $(d)$ of $9.375 \mathrm{~mm}$, increasing the value of $d$ will cause grating lobes to occur and decreasing value of $d$ will increase coupling between patches thereby decreasing performance in both the cases. Therefore, inter-element spacing between the antenna elements and number of elements used in arrays should be kept in mind while designing these antennas. Total area occupied by designed system is $75 \times 75 \mathrm{~mm}$.

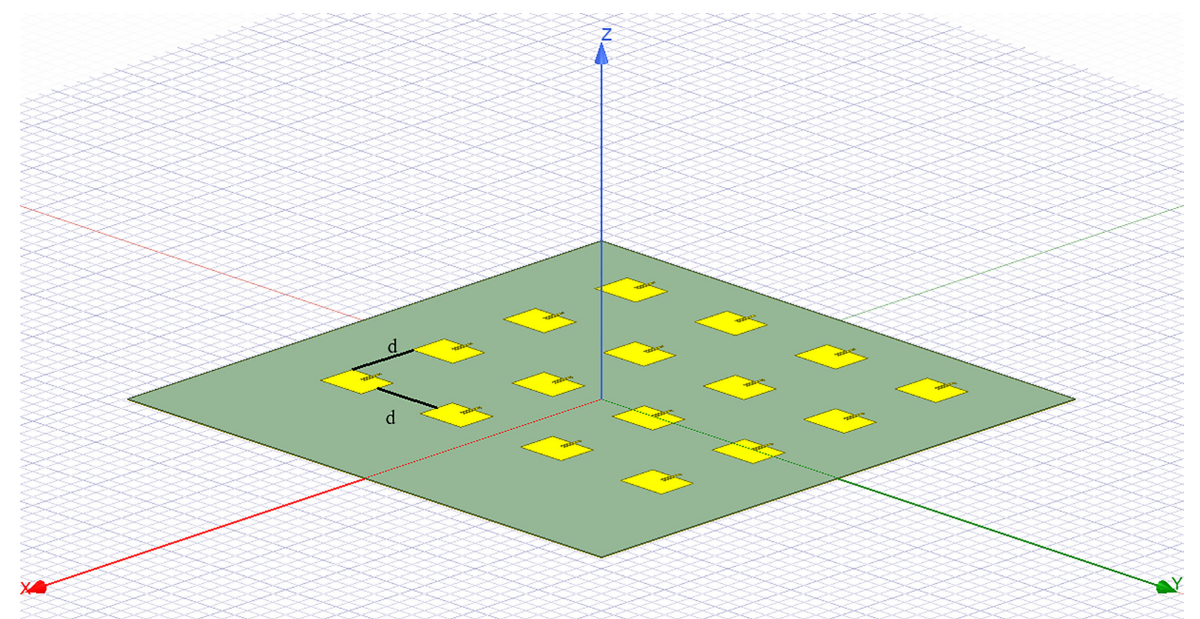

Antenna array design on flexible substrate 
FEBE 1,1

\section{0}

\section{Simulation results and discussion}

The initial simulations of unit microstrip antenna are performed from the dimensions obtained from design equations (Balanis, 2005) and mentioned in Table 3. Further optimization of the dimensions is performed to achieve good resonance. Ansys ${ }^{\circledR}$ Electronics desktop, HFSS (high frequency structure simulator) is used to simulate both the unit patch and array antenna performances (Ansys, 2021).

\subsection{Unit patch antenna}

The return loss $\left(S_{11}\right)$ plot for the unit patch antenna is shown in Figure 4. The value of $S_{11}$ is equal to $-45.07 \mathrm{~dB}$ at the resonance frequency. The $-10 \mathrm{~dB}$ bandwidth of the antenna is $226.2 \mathrm{MHz}$. Similarly, Figure 5 presents the antenna gain having maximum value of $4.8 \mathrm{~dB}$. Antenna gain is one of the important parameters to determine antenna performance, which is defined in Eq. (2) as product of antenna efficiency and directionality.

$$
G=e \times D
$$

Figure 6 shows the far-field radiation pattern of the unit patch antenna with maximum radiation in broadside direction $\theta=0^{\circ}$ direction and minimum radiation in direction of $\theta=90^{\circ}$.

\subsection{Antenna array}

Using the unit patch antenna, an antenna array is modeled and simulated. Figure 7 shows return loss $\left(S_{11}\right)$ of the antenna array. A frequency shift of $20 \mathrm{MHz}$ is noticed due to coupling between elements as shown in Figure 8. Mutual coupling between array elements is

Table 3.

\begin{tabular}{ll} 
Parameters $\quad$ Analytic dimensions \\
\hline
\end{tabular}

Optimized dimensions

\section{Figure 4.}

Return loss $\left(S_{11}\right)$ for proposed unit patch antenna

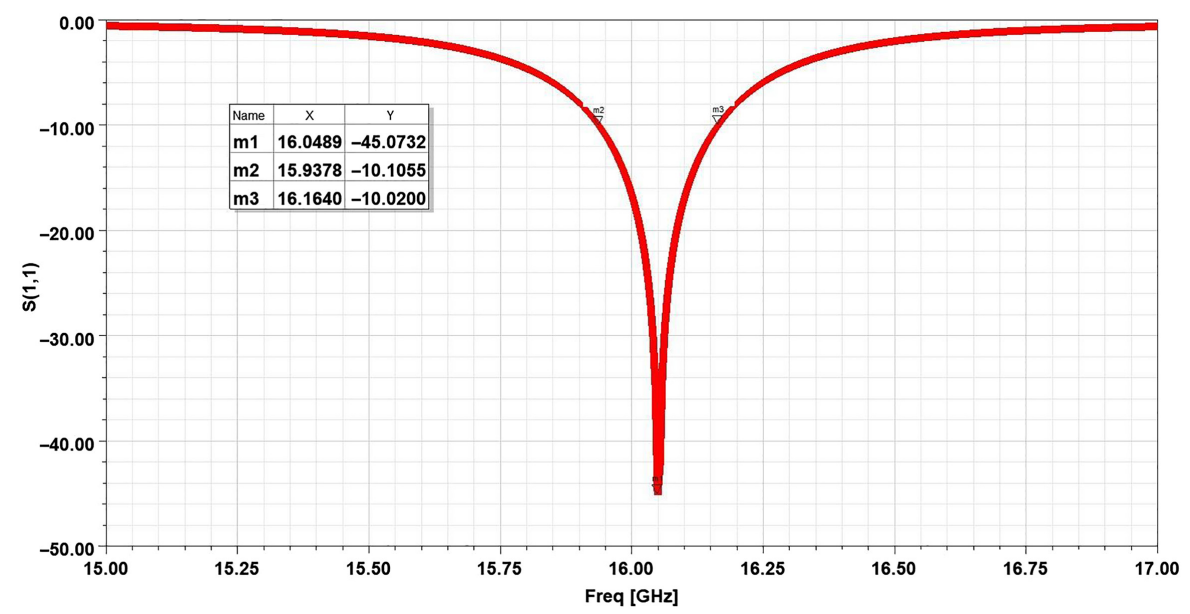




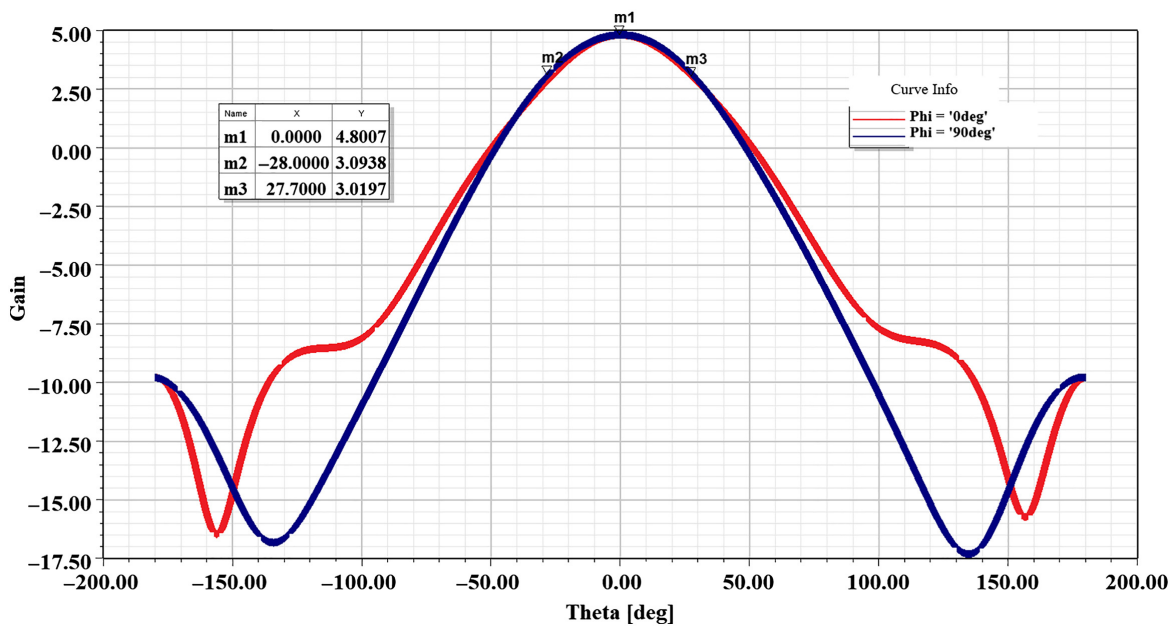

Antenna array design on flexible substrate

61

Figure 5.

Gain plot for proposed patch antenna

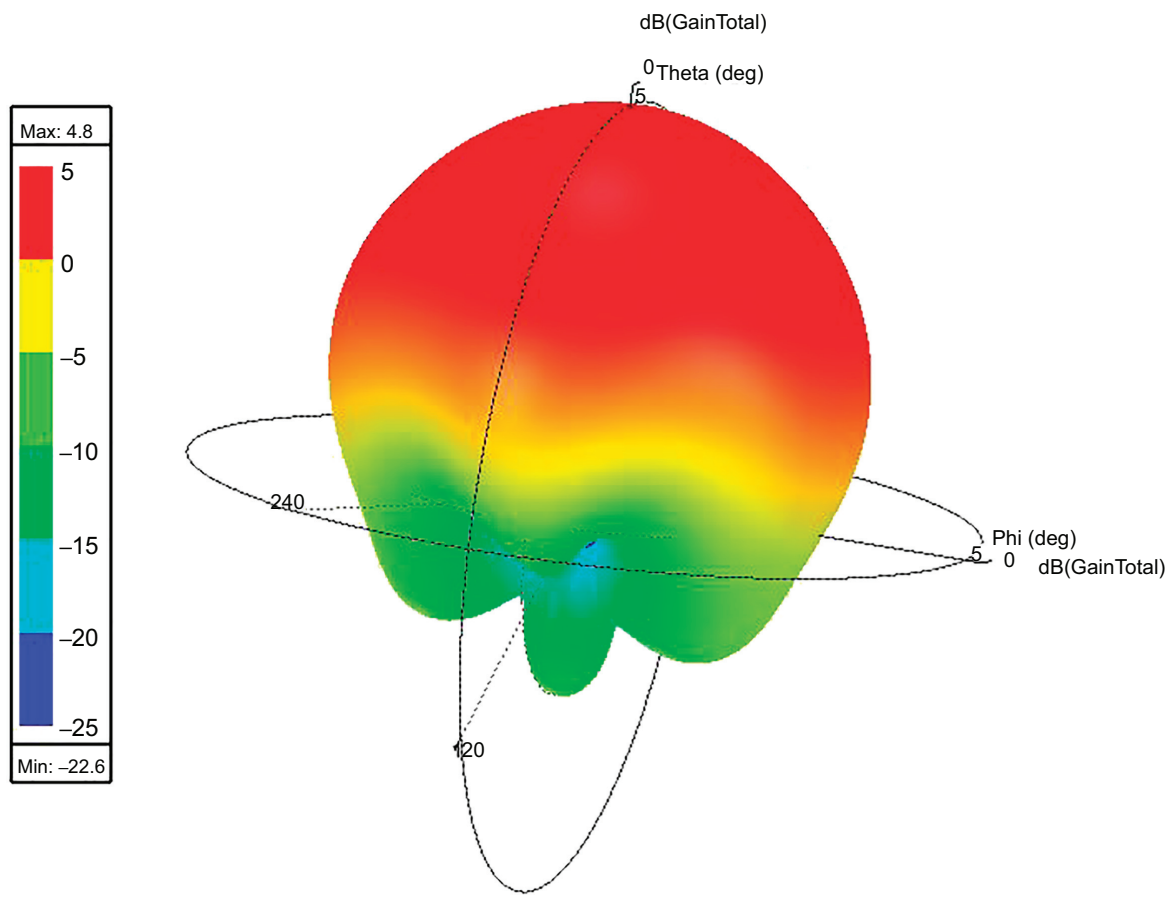

Figure 6. Far-field radiation pattern for proposed patch antenna

considerably less than $-35 \mathrm{~dB}$ (see Figure 8). Minimum value of $S_{11}$ is -29.16 of 2 nd port and maximum value of $S_{11}$ is equal to -41.52 of 1 st port. Impedance bandwidth of $240 \mathrm{MHz}$ is achieved. Similarly, Figure 9 shows gain plot of the designed antenna array, which depicts value of gain at $\mathrm{phi}=0^{\circ}(x-z$ plane $)$ and at $\mathrm{phi}=90^{\circ}(y-z$ plane $)$. The maximum value of gain 


\section{FEBE 1,1}

62

Figure 7.

Return loss $\left(S_{11}\right)$ for proposed antenna arrays
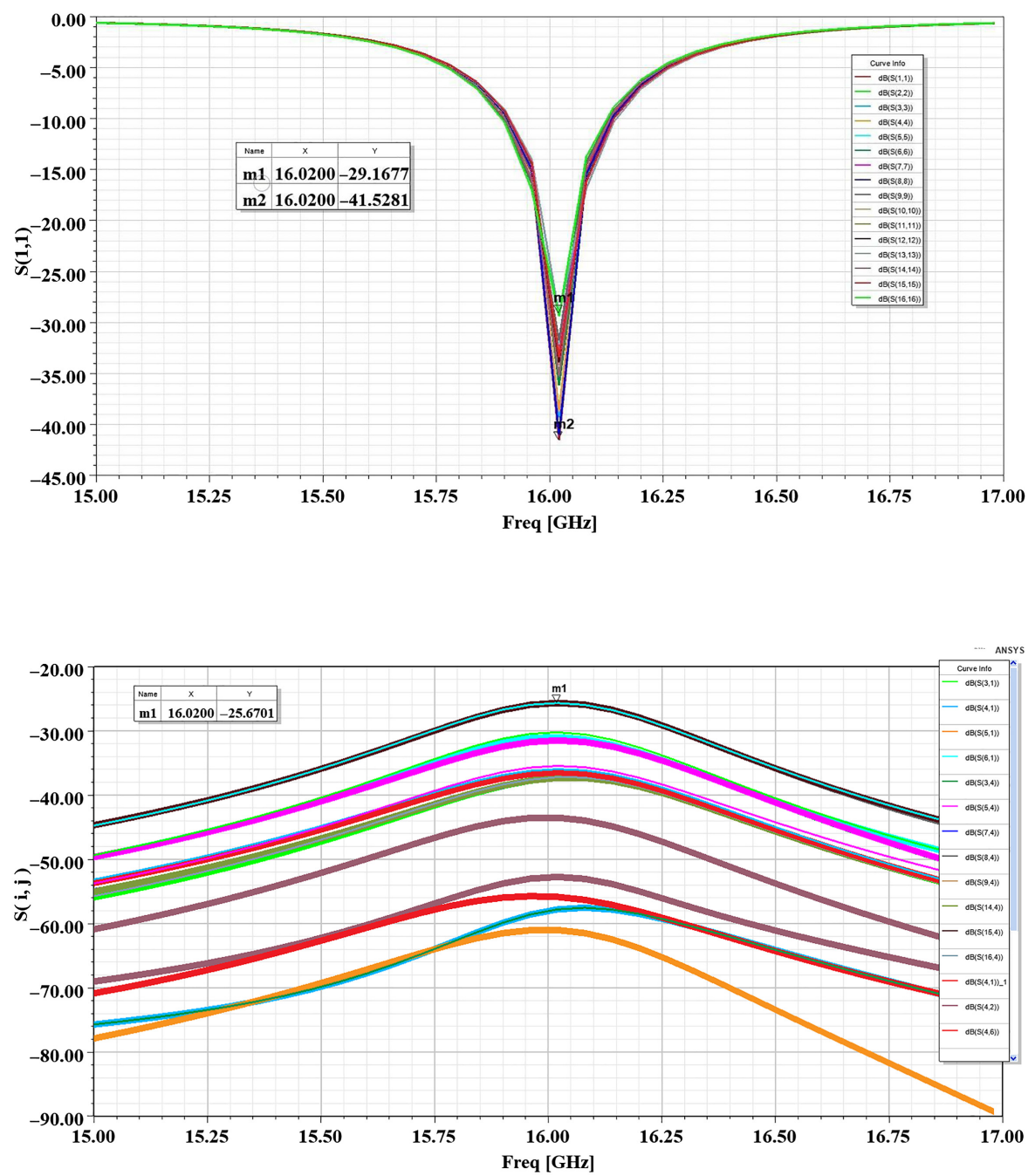

Figure 8.

Mutual coupling $\left(S_{i j}\right)$ between antenna array elements

obtained at $\theta=0^{\circ}$ is $16.38 \mathrm{~dB}$ with $3 \mathrm{~dB}$ beam width of $29.4^{\circ}$. Figure 10 shows the variation of radiation efficiency with frequency, which is $36.67 \%$ at resonance frequency and decreases as frequency is increased. Figure 11 presents radiation pattern of array antenna. The main beam is narrower and focused than the single element which is desired for power transfer, side and back lobes have less power than main lobe. Figure 12 presents co- and cross-polarization field components of antenna. Cross-polarization level is well below $-34.23 \mathrm{~dB}$. Figure 13 provides antenna scanning range of $-15^{\circ}$ to $+15^{\circ}$ in both the elevation and azimuth planes with gain value more than $14 \mathrm{~dB}$. Due to dielectric losses of flexible Kapton substrate, its radiation efficiency is low at $36.67 \%$. Table 4 summarized both unit patch and array antenna result outcomes. Both bandwidth and gain increases in array. Increment in gain is obvious because more elements are used but bandwidth also slightly increases due to resonance coupling between array elements. 


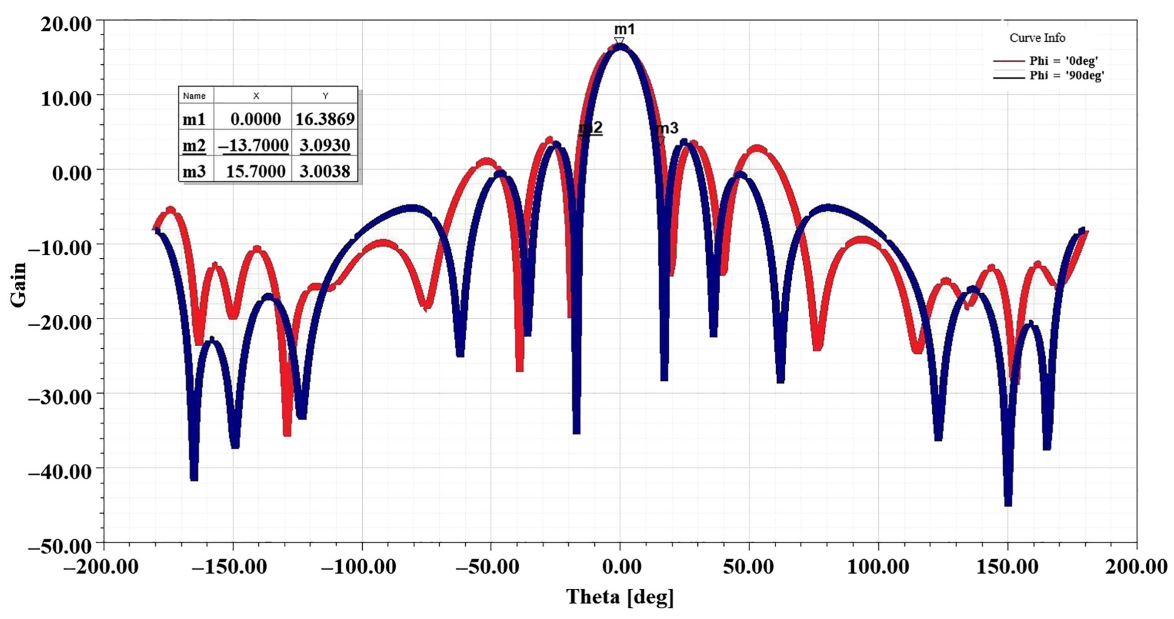

Antenna array design on flexible substrate

63

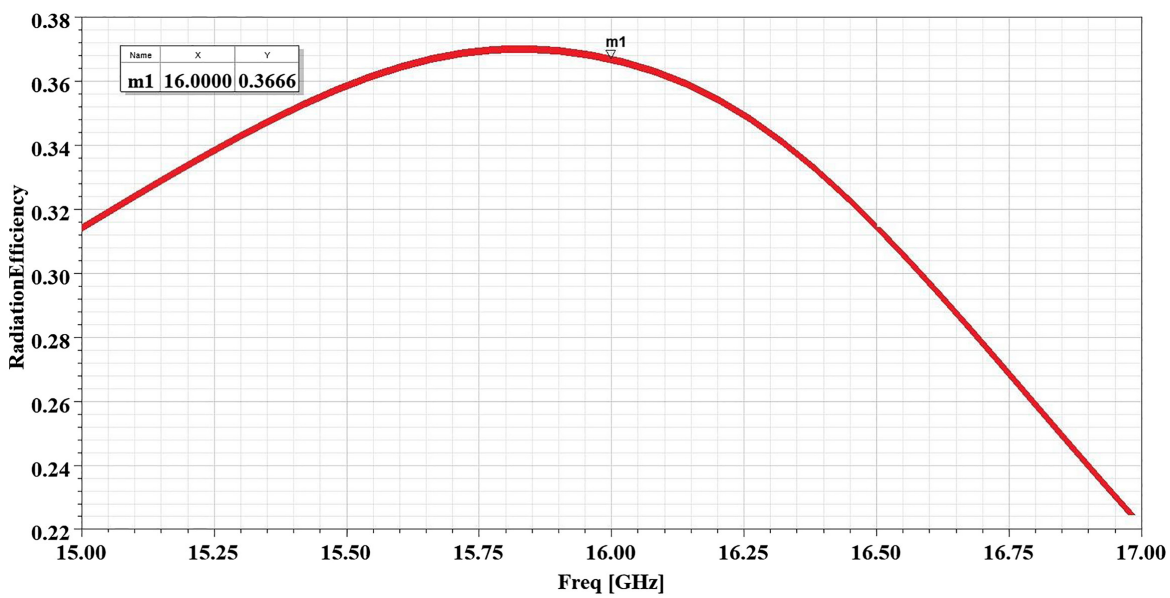

Figure 10. Radiation efficiency versus frequency

\section{Conclusion and future scope}

In this work, a $4 \times 4$ microstrip antenna array using flexible Kapton polyimide substrate is proposed to operate at $16 \mathrm{GHz}$ for WPT application. It exhibits high simulated broadside gain of $16.38 \mathrm{~dB}$ along with $-10 \mathrm{~dB}$ bandwidth of approximately $240 \mathrm{MHz}$. Also, it offers a wide beam width of $29.4^{\circ}$ with very low cross-polarization levels of $-34.23 \mathrm{~dB}$. The antenna array beam can scan from $-15^{\circ}$ to $+15^{\circ}$ in both the elevation and azimuth planes. The proposed antenna array is capable of focusing the electromagnetic energy toward a targeted user terminal with an efficiency of $36.67 \%$. The designed antenna uses flexible Kapton polyimide substrate which provides conformability to the designed antenna. Thus, promising results make this antenna array a good probable candidate for future wireless charging applications. In future we are going to perform bending of the array structure and how it will affect different characteristics of antenna. Bending of designed array antenna on a PVC plastic cylinder is shown in Figure 14. 
FEBE

1,1

64

Figure 11.

Far-field radiation pattern for proposed antenna array
Figure 12.

Co and cross-

polarization fields of antenna array
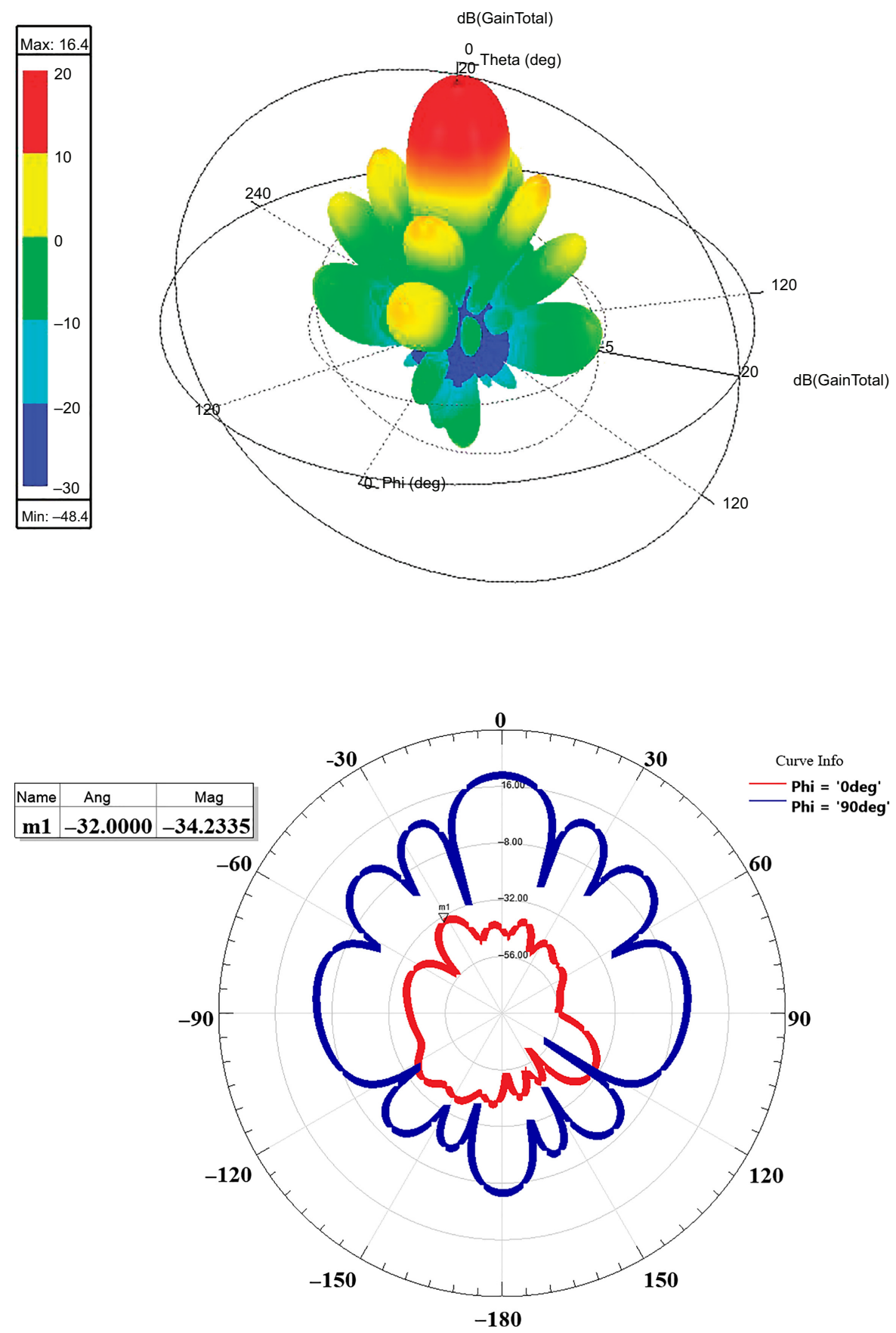


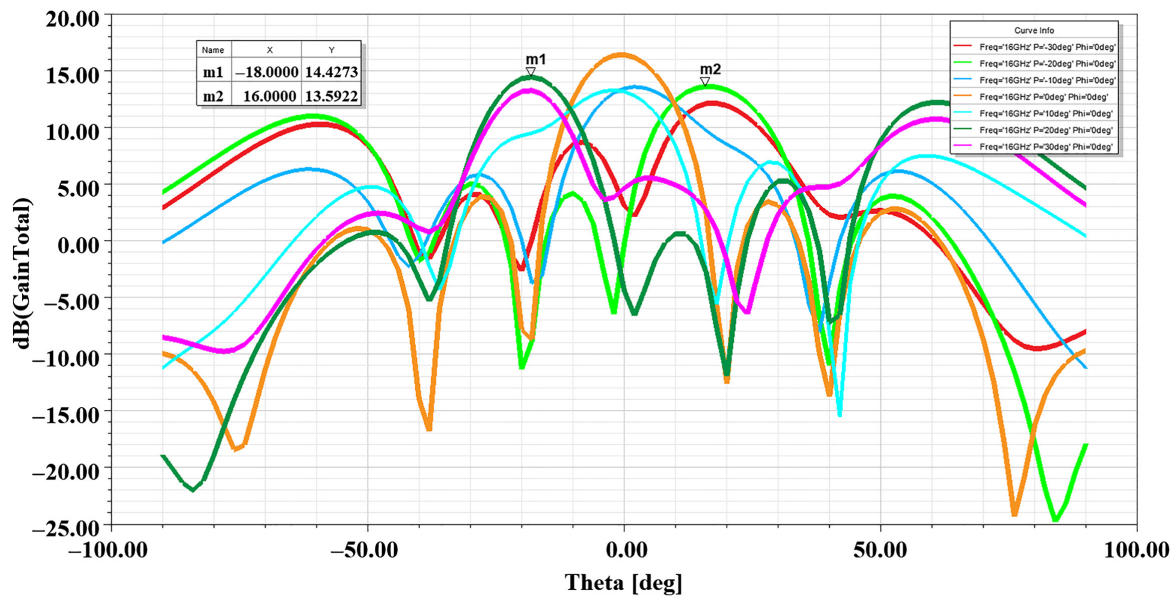

Antenna array design on flexible substrate

\begin{tabular}{lcc}
\hline Parameters & Unit Antenna & Antenna array \\
\hline Bandwidth & $226.2 \mathrm{MHz}$ & $240 \mathrm{MHz}$ \\
Peak gain & $3.02 \mathrm{~dB}$ & $16.38 \mathrm{~dB}$ \\
Radiation efficiency & $46.187 \%$ & $36.67 \%$ \\
Beam width & $55.7^{\circ}$ & $29.4^{\circ}$
\end{tabular}

Table 4. Antenna array parameter obtained after simulation

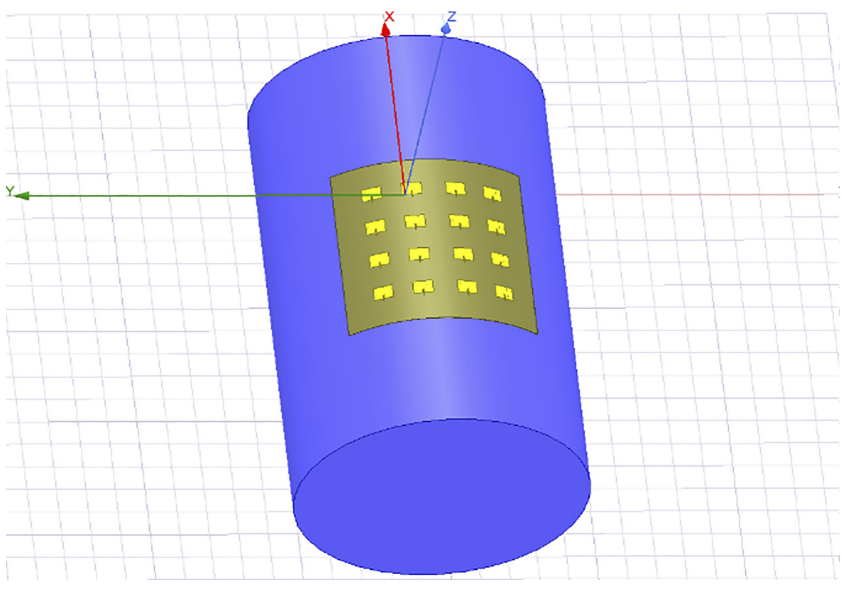

Figure 14.

Study of bending structures

\section{References}

Ansys (2021), Ansys® Electronics desktop, HFSS-v20, Ansys, available at: www.ansys.com.

Bakytbekov, A., Nguyen, T.Q., Huynh, C., Salama, K.N. and Shamim, A. (2018), "Fully printed 3D cube-shaped multiband fractal rectenna for ambient RF energy harvesting", Nano Energy, Vol. 53, pp. 587-595. 
FEBE 1,1

Balanis, C.A. (2005), Antenna Theory: Analysis and Design, John Wiley \& Sons, New York.

Bao, K., Zekios, C.L. and Georgakopoulos, S.V. (2019), "A wearable WPT system on flexible substrates", IEEE Antennas and Wireless Propagation Letters, Vol. 18, INSPEC Accession No. 18636396, pp. 931-935.

Basnayaka, Chathuranga, M.W., Chathuranga, D. and Madhushika, W.D.S. (2020), "Wireless energy transmission for access limited underground sensors", The University of Ruhuna, 2013/GR_09.

Bush, S.F. (2014), Smart Grid: Communication-Enabled Intelligence for the Electric Power Grid, John Wiley \& Sons, p. 118.

Choudhary, V., Satendar Pal, S., Vikash, K. and Deepak, P. (2011), "Wireless power transmission: an innovative idea", International Journal of Educational Planning and Administration, Vol. 1 No. 3, pp. 203-210.

Dunbar, S., Wenzl, F., Hack, C., Hafeza, R., Esfeer, H., Defay, F. and Popovic, Z. (2015), "Wireless farfield charging of a micro-UAV”, IEEE Wireless Power Transfer Conference (WPTC), pp. 1-4.

Erfani, R., Marefat, F., Sodagar, A.M. and Mohseni, P. (2017), "Transcutaneous capacitive wireless power transfer (C-WPT) for biomedical implants", IEEE International Symposium on Circuits and Systems (ISCAS), ISSN No. 2379-447X, pp. 1-4.

Erfani, R., Marefat, F., Sodagar, A.M. and Mohseni, P. (2018a), "Modeling and characterization of capacitive elements with tissue as dielectric material for wireless powering of neural implants", IEEE Transactions on Neural Systems and Rehabilitation Engineering, Vol. 26 No. 5, pp. 1093-1099.

Erfani, R., Marefat, F., Sodagar, A.M. and Mohseni, P. (2018b), "Modeling and experimental validation of a capacitive link for wireless power transfer to biomedical implants", IEEE Transactions on Circuits and Systems II: Express Briefs, Vol. 65 No. 7, pp. 923-927.

García, M.P., Olivia-Sanchez, J., Sanchez-Iborra, R., Cañete-Rebenaque, D. and Gomez-Tornero, J.L. (2019), "Dynamic wireless power transfer for cost-effective wireless sensor networks using frequency-scanned beaming”, IEEE Access, Vol. 7, pp. 8081-8094.

Gangwar, A.K. and Alam, M.S. (2016), "A SSRR based multiband reconfigurable monopole antenna”, IEEE Students' Technology Symposium (TechSym)', Kharagpur, 2016, INSPEC Accession No. 16726757, pp. 208-211.

Haerinia, M. and Noghanian, S. (2019), “A printed wearable dual-band antenna for wireless power transfer", Sensors, Vol. 19 No. 7, pp. 1-10.

Hashemi, M.R.M., Fikes, A.C., Gal-Katziri, M., Abiri, B., Bohn, F., Safaripour, A. and Hajimiri, A. (2019), "A flexible phased array system with low areal mass density", Nature Electronics, Vol. 2 No. 5, pp. 195-205.

Heo, E., Choi, K.Y., Kim, J., Park, J.H. and Lee, H. (2017), “A wearable textile antenna for wireless power transfer by magnetic resonance", Textile Research Journal, Vol. 88 No. 8, pp. 913-921.

Ibrahim, F.N., Jamail, N.A.M. and Othman, N.A. (2016), "Development of wireless electricity transmission through resonant coupling", 4th IET Clean Energy and Technology Conference (CEAT).

Jadidian, J. and Katabi, D. (2014), "Magnetic MIMO: how to charge your phone in your pocket", in Proceedings of the 20th Annual International Conference on Mobile Computing and Networking, pp. 495-506.

Kirtania, S.G., Elger, A.W., Hasan, M.R., Wisniewska, A., Sekhar, K., Karacolak, T. and Sekhar, P.K. (2020), "Flexible antennas: a review", Micromachines, Vol. 11 No. 9, pp. 1-43.

Lu, X., Wang, P., Niyato, D., Kim, D.I. and Han, Z. (2016), "Wireless charging technologies: fundamentals, standards, and network applications", IEEE Communications Surveys and Tutorials, Vol. 18 No. 2, pp. 1413-1452.

Palazzi, V., Hester, J., Bito, J., Alimenti, F., Kalialakis, C., Collado, A. and Tentzeris, M.M. (2018), “A novel ultra-lightweight multiband rectenna on paper for RF energy harvesting in the next 
generation LTE bands", IEEE Transactions on Microwave Theory and Techniques, Vol. 66 No. 1, pp. 366-379.

Patil, P.S. and Padaganur, S. (2018), "Challenging issues in wireless power transmission methods a survey", International Journal of Scientific and Technology Research, Vol. 7 No. 8, pp. 136-139.

Peng, J.J., Qu, S.W., Xia, M. and Yang, S. (2020), "Wide-scanning conformal phased array antenna for UAV radar based on polyimide film", IEEE Antennas and Wireless Propagation Letters, Vol. 19 No. 9, pp. 1581-1585.

Pham, D., Subbaraman, H., Xu, X., Chen, M.Y. and Chen, R.T. (2011), "Light weight and conformal 2-bit, 14 phased-array antenna with CNT-TFT based phase-shifter on a flexible substrate", IEEE Transaction Antennas Propagation, Vol. 59 No. 12, pp. 4553-4558.

Rayes, M.M.E., Nagib, G. and Abdelaal, W.G.A. (2016), "A review on wireless power transfer", International Journal of Engineering Trends and Technology (IJETT), Vol. 40 No. 5, pp. 272-274.

Sharma, H. (2016), "Study \& survey on wireless charging and technology", International Journal of Engineering Sciences and Research Technology, Vol. 5 No. 12, pp. 717-718.

Sheik Mohammed, S., Ramasamy, K. and Shanmuganantham, T. (2014), "Wireless power transmission - a next generation power transmission system", International Journal of Computer Applications (0975 - 8887), Vol. 1 No. 13, pp. 102-105.

Subbaraman, H., Pham, D.T., Xu, X., Chen, M.Y., Hosseini, A., Lu, X. and Chen, R.T. (2013), "Inkjetprinted two-dimensional phased-array antenna on a flexible substrate", IEEE Antennas and Wireless Propagation Letters, Vol. 12, pp. 170-173.

Valenta, C.R. and Durgin, G.D. (2014), "Harvesting wireless power: survey of energy-harvester conversion efficiency in far-field, wireless power transfer systems", IEEE Microwave Magazine, Vol. 15 No. 4, pp. 108-120.

Wong, W.S. and Salleo, A. (2009), Flexible Electronics: Materials and Applications, Springer Science and Business Media, CA.

Yang, Z., Takacs, A., Charlot, S. and Dragomirescu, D. (2016), "Flexible substrate technology for millimeter wave wireless power transmission”, Wireless Power Transfer, Vol. 3 No. 1, pp. 24-33.

\section{Corresponding author}

Habeeba Khan can be contacted at: habeebakhan0611@gmail.com
Antenna array design on flexible substrate 